Session 2392

\title{
TEACHING GENDER ISSUES TO UNDERGRADUATE ENGINEERING STUDENTS
}

\author{
Ingrid H. Soudek \\ Division of Technology, Culture, and Communication \\ School of Engineering and Applied Science \\ University of Virginia
}

As more women are graduating from Engineering Schools and entering work environments that are traditionally male, it is important to educate students, male and female, on gender issues. The School of Engineering and Applied Science at the University of Virginia has a Division of Technology, Culture, and Communication which offers an array of courses which address the interface between technology and society, technical writing and oral presentation, as well as engineering ethics. We have found that teaching gender issues is very effective when coupled with the teaching of ethics and values of professionals. In this paper, I discuss the specific materials, methods and basic philosophy of teaching that are effective in teaching issues of gender.

My course, TCC 211, "Values of Professionals," explores the value framework, the "calling" of various professions, including engineering. To help students understand how one establishes the values for a particular profession, we talk about applied ethics and about what we consider right and wrong behavior both on the job and in our private lives. This, of course, includes gender and race issues. To address those issues, I use a deductive method: I start with general concepts first; then, once a frame of reference has been established, I address the specific issues through the use of examples from the course reading, news items, and personal narratives.

The book I use to introduce the class to some basic ethical concepts is Sissela Bok's Lying. Bok gives an overview of some classical theories of ethics and how various philosophers viewed the concept of lying, including her own perspective on different kinds of lies. She applies these ideas to contemporary professions and well-documented examples of lying by professionals, such as politicians and journalists in the Watergate case, doctors lying to dying patients, etc. We use these examples to explore in class how important truth-telling is in achieving the values of professionals. It also demonstrates to the students that it is of the utmost importance to consider the long-range consequences of one's actions, that a knee-jerk, self-protective reaction to an immediate dilemma can have dire consequences in the long run.

In order to develop the habit of thinking what is the best thing to do in the long run and for all concerned, I follow Bok with a section on "moral autonomy," what it is, and how to achieve it. I use the psychological theories of moral development presented by Lawrence Kohlberg and Carol Gilligan. Their theories are particularly useful in teaching gender issues because both start out with the same basic ideas, but Gilligan shows how gender affects course of actions taken in 
response to a "dilemma" and how the interpretation of women's choices of action consistently are interpreted as falling short of moral autonomy. (Gilligan, 1982, 17-23)

Kohlberg believes that the goal of moral development is to reach moral autonomy, which, according to him, few people are able to achieve. On the way to moral autonomy, an individual goes through three stages of moral development: 1. The Preconventional Level is the most primitive and is seen mostly in young children and a few adults. The individual is only concerned with the desire to satisfy immediate needs and avoid punishment, and he or she will defer without question to the demands of those much more powerful. 2. The Conventional Level is the one in which most people operate. They use the norms of the group, whatever they happen to be, as the correct standards of morality. Identification with the group is most important and it governs their actions and responses to dilemmas. Thus society or the family group, for example, will dictate an individual's course of action which he or she will adhere to without question. 3 . The Postconventional Level is the last and highest stage of moral development. This is where moral autonomy can be achieved because individuals will base their actions on principles which are not based on strict self-interest or the interests of a particular group. Rather, the individuals act on sets of principles about right and wrong because these principles are right in themselves and separate from the selfish concerns of an individual or group. Thus, a person might follow the Golden Rule ("Do unto others as you would have them do unto you"), as a principle that can be applied universally and will maintain the moral integrity of the people involved. A person overcomes the passive acceptance of the values of the dominant culture or group and exercises moral reasoning based on fundamental principles of what is philosophically right and wrong. (Kohlberg, 1971; Martin \& Schinzinger, 1989, 17-18)

Kohlberg developed his theory of moral development by observing, over a period of several years, male subjects only. To test the level of moral development in his subjects, he uses a particular example, "Heinz's Dilemma," in his questionnaires and interviews. In this well-known example Heinz's wife is dying of cancer and there is only one drug that can save her. The drug is available only from one pharmacist who invented the drug and who is charging a price that Heinz cannot afford. Heinz is unable to borrow enough money to buy the drug, nor is he able to persuade the pharmacist to sell it to him for less. So, finding no other way out of the dilemma, Heinz breaks into the pharmacy and steals the drug. The question asked [on the questionnaire] is, "Was the theft morally right or wrong?" If the subject answered that Heinz did wrong because he broke the law, or if he answered that according to the laws of God, life is more important and thus Heinz is right, Kohlberg determined the subject to be at the conventional level. If, however, the subject answered that the right to life is inherently more important than the right to profit, based on universal principal, then Kohlberg determined the subject had reached the Postconventional Level and showed moral autonomy. When women took this test, according to Kohlberg's rating, they usually stayed at the Conventional Level because they could not justify stealing the drug without first making other attempts to get it. They would make all kinds of suggestions for getting the drug that did not involve stealing it. This hesitancy to steal the drug was interpreted, according to Kohlberg's scheme, as adhering to conventions and thus kept women morally at the Conventional Level. (Kohlberg, 1971; Martin \& Schinzinger, 1989, 19)

Gilligan took issue with Kohlberg's interpretation of women's levels of moral development. She was a student and then a colleague of Kohlberg; in her book, In A Different Voice, she charges 
that Kohlberg's interpretations of female responses to moral dilemmas are "male biased." Gilligan points out that men are generally preoccupied with abstract rules and rights, whereas women are more concerned with relationships and caring for others. She states that "the very traits that traditionally have defined the goodness' of women, their care for and sensitivity to the needs of others, are those that mark them as deficient in moral development" (Gilligan, 1982, 18). Gilligan's own studies and her interpretation of Kohlberg's data lead her to different conclusions:

The psychology of women that has consistently been described as distinctive in its greater orientation toward relationships and interdependence implies a more contextual mode of judgment and a different moral understanding. Given the differences in women's conceptions of self and morality, women bring to the life cycle a different point of view and order human experience in terms of different priorities (Gilligan, 1982, 22).

Gilligan recasts Kohlberg's three levels of moral development and includes an ethics of caring. The Preconventional Level stays the same, but the Conventional Level adds the cultural stereotype that women give up their personal interests to serve the needs of others. At Gilligan's Postconventional Level the individual must be able to balance the ethics of caring about other people vs. exercising one's rights. This is achieved through "context-oriented" reasoning (Gilligan, 1982, 100). In other words, moral autonomy can be adherence to universal principles, human rights, as well as caring for other people when in a community based on personal relationships (Kohlberg, 1971; Martin \& Schinzinger, 1989, 20).

Achieving moral autonomy thus requires understanding the principles involved in moral dilemmas and also making a conscious choice of higher moral values. The example of Heinz's Dilemma helps students see the complexity involved in making a correct choice, and that this requires using their imagination and a belief that there may be another, more favorable solution. It also alerts them to some of the cultural differences between men and women, and that this applies to what they will encounter in the work place.

The next step in teaching gender issues to our mostly male engineering classes is specifying what the stereotypes are for males and females. I encourage them to come up with lists of their own; I also present them with one generated by Evelyn Fox Keller in her article, "Women, Science, and Popular Mythology." Fox Keller contrasts the mythology of science with the stereotypes of women. For example, "science deals with things and women with people ; the scientific mind is male, nature is female; the aim of science is the domination of nature; science seeks power, women seek harmony" (Fox Keller, 198 , 132-133). We use a case study approach to discuss these cultural perceptions; students bring their personal experiences to the discussions, sometimes using their parents or friends for examples when their own experiences are insufficient. I also encourage them to use news items and to support perceptions with facts wherever possible. There are always some women in my classes (at least $20 \%$ of the students), so when we get to this part of the course, there is enough diversity in the classroom to make the discussions interesting. The students have been in the course long enough and know each other at this point to have enough trust in the discussion process to take chances. When the discussion reaches a dead end, I may present a contrarian point of view to restart the discussion along some other path. The students use of "narratives" to make their points or explain their perceptions is 
very effective; they tell their "stories" and those stories define for them certain situations or even concepts.

When talking about specific stereotypes, it can be instructive when students "role play" the opposite sex stereotype, for example. When males are asked to imagine themselves in situations that females sometimes find difficult to deal with, and are asked to find ways out of the dilemma, they often show a new understanding of such situations. In the same way, females learn that certain dilemmas are faced by males as well as females, and this helps both genders to better understanding.

Fox Keller's stereotypes provide a good point of departure to talk about the specific issue of gender and science. I have used her book, Reflections on Gender and Science, and while some of the students found it interesting, most of them lacked an historical and cultural perspective to appreciate many of her points. The discussions have been better when I summarize some her ideas and also have them watch Bill Moyer's interview with her. Since I am teaching engineering students, at least the females consider it a given that women also belong in science. The male students rarely verbalize a contrary opinion in class , but both male and female students point out that there are still male professors, on the predominantly male faculty, who believe that women have no place in engineering and science. We talk about why this is so and how this might be changed. Some of the women students have changed majors to get away from such professors, others stay on to "show" them. But very important to their success is that there is some support network, which will often include male students and other male professors. A good reference for this part of the discussion is Sue V. Rosser's, Female-Friendly Science. Rosser writes about methods to attract female students to science. During these discussions, it becomes obvious that a good proportion of the male students feel uncomfortable if it is not made absolutely clear that there will be no male bashing or "blaming." The point of these discussions and the readings is to get understanding, to learn to walk in someone else's shoes and to find solutions for difficult situations. It is also important to clarify that these issues are not just about equality of the sexes in schools and the workplace, but also about recognizing, accepting and valuing diversity. Evelyn Fox Keller provides a good example of the value of bringing a different approach to science when she talks about the scientist Barbara McClintock. McClintock brought a different approach to science and occupies a place in the history of genetics that "is marked by difference at every turn" (Fox Keller, 1985, 158).

Her major criticism of contemporary research is... that much of the work is done because one wants to impose an answer on it- they have the answer ready, and they want the material to tell them, so anything it doesn't tell them, they don't recognize as there, or they think it's a mistake and throw it out... If you'd only just let the material tell you' (Fox Keller quoting McClintock, 1985, 162).

Barbara McClintock's different approach to scientific study, her "feeling for the organism," as Fox Keller puts it, in part grows out of being socialized as a female. It has some origin in what Gilligan calls "connectedness" to the world around her. McClintock's non-traditional view of science helped advance the study of biology (genetics). This is one of the examples I use in class to demonstrate how bringing diverse viewpoints to knowledge or solving problems can enrich and enlighten. But it is also important that this be facilitated by a nurturing atmosphere that allows individuals to do their best work. 
More examples of both gender and race issues come up when the class reads and discusses Having Our Say: The Delany Sisters' First Hundred Years, by Sarah and A. Elizabeth Delany (with Amy Hill). The Delany sisters are black, but some of the problems they had to deal with in their lives had to do with being female, and mirrored some of the history of women's emancipation. They chose, for example, to become professionals, dentist and teacher, over marriage and motherhood. In their time, they felt that they had to be one or the other; they did not believe that it would be possible to combine career and marriage. This is not only an example of values of individuals, but values of the society at the same time. At one period in American history, married women could not be teachers or nursing students, for example. Talking about the lives of the Delany sisters gives the students a historical perspective, as well as provokes lively discussions about career and marriage today and how couples cope with this. There usually is a male student who admits reluctantly that he might consider staying home with the kids if his wife makes more money than he. Frequently male students will say that they would feel less manly if they did not work outside the home, but that they would expect their wives to put careers on hold to raise small children. There are also debates on how living in a two-career household affects children; typically both pros and cons are represented in the class. There is always one female who will say that she feels her working mother was a good example and inspired her to pursue a career.

Discussing career issues in an engineering school environment is always very intense because the women in the class usually think they know what their career path will be or should be. They already have ideas about what their specific jobs will be like and even about the conflicts they might have to face, outside the job as well as on the job. Some of them have had summer jobs in engineering firms and can give examples of the difficulties women face when working in a traditionally male environment. We talk about what some companies have done to ease the transition for women into such a work place. Inevitably the topic of sexual harassment comes up.

Many companies ask their employees to go to seminars that deal with sexual harassment. Talking about this topic is always enlightening to the whole class because it becomes clear very quickly that, again, males and females have different perspectives. Sometimes it is difficult to agree on what constitutes sexual harassment. The examples we use include a female boss harassing a male worker and how that male worker has a difficult time being taken seriously when he lodges a complaint; his complaint is taken as a joke, or, as his good luck. The students learn about a class of behavior and comments that might be offensive to someone, and that this can poison a workplace. They agree that the best strategy for their own behavior is to avoid any sexual overtones in their conversations or behavior with fellow workers; even complimenting on looks or touching someone on the shoulder can be misconstrued. We also talk about strategies for dealing with unwanted attention from co-workers or the boss.

All of these discussions are tied to the values of our society and those espoused by various professions; we value and, in some instances uphold by law, the rights of individuals to have equal opportunities in pursuing what we call the "American dream." Yet to do this successfully, we must value our differences. We consider it ethical and right to care about all segments of society, including all races, religions, and genders. While our students will say that they believe 
in this in general, they often do not know what it really means in specific, and how this affects them personally. Many engineering students, for example, have no awareness that there are sometimes hostile environments for women who want to study and work in science and engineering. They think that this was the case "a long time ago" and do not want to hear about it. Some of the male students are only interested in talking about discrimination when they believe they are the victims of it in job searches. As their teacher, I consider it my obligation to take that reluctance and narrow interest in discrimination and broaden it, so that the students understand that their own rights and interests are directly connected to the rights of others and the society at large. They need to see that their own well-being also depends on the well-being of those around them, and that this will come about if they actively participate in creating a nurturing environment. Through the readings, the discussions, personal narratives, role playing, and case studies, the students profess at the end of the semester, in their papers, comments in class, and on the final exam, to have gained greater insights and broader views of the issues of gender.

Finally, I have been asked a number of times, "Can a male professor teach gender as effectively as a female, particularly to women engineering students ?" From my experience and observations, it makes no difference whether the professor is male or female. The most important aspect of teaching gender, in my opinion, is to establish trust in the classroom. Students need to know that they will not be ostracized, ridiculed, ignored, put down, embarrassed or patronized when giving their opinions and telling of their experiences. On the first day of classes I point out to my students that we will explore some controversial points of view and that they can agree and disagree, but must always keep in mind that we are discussing ideas, not individual people in the class. No one is going to tell them what to think, either through the reading or lectures in class. The whole idea is to keep an open mind and to entertain a new point of view, which applies to the professor as well. The key for the teacher, I think, is to encourage free expression, show respect for the student's opinions, act as devil's advocate, and, most of all, to have a positive attitude about the discussions.

\section{REFERENCES}

Bok, Sissela. 1978. Lying: Moral Choice in Public and Private Life. Vintage Books

Delany, Sarah and A. Elizabeth with Amy Hill. 1993. Having Our Say: The Delany Sisters' First 100 Years.

Keller, Evelyn Fox. 1983. "Women, Science, and Popular Mythology," Machina Ex Dea: Feminist Perspectives on Technology. Pergamon Press. 130-145.

Keller, Evelyn Fox. 1985. Reflections On Gender and Science. Yale University Press.

Kohlerg, Lawrence. “The Philosophy of Moral Development,” Vol. 1, Harper and Row, 1971.

Gilligan, Carol. 1982. In a Different Voice: Psychological Theory and Women's Development. Harvard University Press.

Martin, Mike W., and Schinzinger, Roland. 1989. Ethics in Engineering, 2nd Edition. McGraw Hill Book Company.

Rosser, Sue V. 1990. Female Friendly Science. Pergamon Press. 